\title{
EL TRABAJO INFANTIL: DE LA DISCUSIÓN TEÓRICA A LA REALIDAd ETNOGRÁFICA. MOTIVACIONES DE LA INFANCIA GUATEMALTECA para trabajar en Tapachula, Chiapas
}

\section{Child Labor: From Theoretical Discussion TO ETHNOGRAPHIC REALITY. Guatemalan Children's Motivations For Working in Tapachula, Chiapas}

\section{Yasmina A. López Reyes}

Resumen: En este artículo se exponen algunas de las motivaciones que llevaron a niñas, niños y adolescentes de Guatemala a tomar la decisión, individual o colectiva, de salir de casa para trabajar en la ciudad de Tapachula. Es a través de dichas motivaciones que podemos acercarnos a entender la manera en que conciben la noción de trabajo desde sus experiencias de vida, la cual puede contraponerse de distintas maneras a aquellos posicionamientos que promueven la erradicación del trabajo infantil. Los datos etnográficos que aquí presento fueron recabados mediante entrevistas y observaciones que me permitieron dar seguimiento a las historias de vida de la infancia trabajadora y corresponden al trabajo de campo realizado en Tapachula, Chiapas, como parte de mi formación académica durante 2013-2014.

Palabras clave: infancia, trabajo, migración, motivación.

\footnotetext{
* Candidata a doctora por la Universidad Iberoamericana, Ciudad de México. Temas de interés: infancia, trabajo y migración de población guatemalteca hacia México, https://orcid. org/0000-0001-7880-0938, correo e.: yasareli@hotmail.com

Fecha de recepción: 1906 18; 2a. versión: 0608 18; Fecha de aceptación: 121018.
}

(cc) EY-NC-ND Páginas 137-165. 
Abstract: This article exposes some of the motivations that led Guatemalan children and adolescents to make the decision, individually or collectively, to leave their homes and go to work in Tapachula city. It is through these motivations that we can try to understand from their life experiences how they conceive the notion of work, which can be opposed in different ways to those positions that promote the eradication of child labor. The ethnographic data presented here were collected through interviews and observations that allowed me to follow the life stories of working children and correspond to the fieldwork carried out in Tapachula, Chiapas, between 2013-2014 as part of my academic training.

Keywords: childhood, job, migration, motivation.

\section{Introducción}

El objetivo de este artículo es poner en contexto a la infancia trabajadora y migrante proveniente de municipios fronterizos de Guatemala hacia la ciudad de Tapachula, Chiapas, con la finalidad de analizar la manera en que las diversas motivaciones inciden en la toma de decisión para trabajar y para migrar, así como sus implicaciones. Dichas motivaciones están circunscritas a condiciones históricas, económicas, sociales y culturales, lo que las hace flexibles y dinámicas.

El texto se divide en dos partes. En la primera, se hace una revisión sobre el concepto de trabajo infantil, que va desde definiciones hasta los posicionamientos políticos y académicos más destacados respecto al tema. En la segunda presento el dato etnográfico, que permite mostrar cómo la realidad sobre el trabajo infantil toma un sentido propio. Ahí se expone cuáles son las motivaciones que lleva a parte de la infancia de Guatemala a migrar y a trabajar dentro y fuera de su país, la mayoría de las veces en condiciones desfavorables. La etnografía está organizada a partir de las siguientes interrogantes: ¿en qué condiciones vive quien 
migra en el lugar de origen?; ¿por qué sale de su lugar de origen?; ¿qué papel tiene la familia en la toma de decisión para migrar y cuáles son las redes de apoyo de quien migra?; ¿por qué elige trabajar en Tapachula?, $\mathrm{y}$ ¿qué factores subjetivos motivan la migración temporal?

\section{Conceptualización de trabajo infantil. Del abolicionismo al derecho a trabajar}

La literatura que aborda la temática sobre este concepto, al igual que el de infancia, es amplia y se ha escrito desde diversas áreas de las ciencias sociales —antropología, sociología, economía, psicología-. Los estudios realizados por varias instituciones gubernamentales y no gubernamentales también han contribuido a su definición. Sin embargo, algunos especialistas en el tema se han dado a la tarea de entender la dinámica laboral de la infancia de una manera distinta al enfocar el análisis de estudio ya no sólo en la categoría de trabajo o de explotación sino también en la propia niñez, donde se destaca la agencia de los sujetos en cuestión con el fin de visibilizarlos, dignificar su labor y emprender acciones que garanticen su acceso a los derechos humanos básicos: alimentación, educación, salud, libertad de expresión y participación, entre otros (Rausky, 2009; Saadeh, 2011; Blanco, 2012; Pérez, 2012; Glockner, 2014).

El debate que gira alrededor del concepto de trabajo infantil dentro y fuera de las ciencias sociales ha sido intenso, sobre todo después de que entra en vigor la Convención sobre los Derechos del Niño de 1989. Leyra (2011) señala dos aspectos importantes en este sentido: primero, que a partir de reformular el concepto de infancia mediante dicha Convención, grupos de investigación multidisciplinaria comenzaron a realizar numerosos estudios sobre infancia en general y el trabajo infantil en particular, para organismos internacionales - OIT, Unicef, por ejemplo- Segundo, que a principios de la década de 1990, "se comenzó a abrir — aún más - la brecha ideológica y política —existente- respecto al trabajo infantil” Leyra (2011: 8-9) lo que derivó en una mayor producción académica y generó dos claros posicionamientos políticos contrapuestos: el enfoque abolicionista y el enfoque de valoración crítica. 
En el abolicionista — y erradicacionista — se puede ubicar a la mayoría de las instituciones gubernamentales, muchas no gubernamentales y a académicos, quienes no están de acuerdo con que la infancia desarrolle actividades laborales, ya que son consideradas nocivas y, además, vulneran los derechos a la educación, la salud, la seguridad, a vivir su propia niñez, de acuerdo con la Convención sobre los Derechos del Niño. Aunque se reconoce que la pobreza en la que vive la mayoría de quienes migran es una de las principales causas que determina la necesidad de trabajar, se argumenta que el trabajo de las niñas, niños y adolescentes sólo conlleva a perpetuar la pobreza, ya que al limitar su acceso a la educación escolar o la deserción a la misma, no les permitirá adquirir competencias que puedan desarrollar en empleos mejor pagados y continuarán desempeñándose en actividades informales y poco calificadas, con bajos salarios y en condiciones de explotación y riesgo.

Entre las instituciones más importantes que están en desacuerdo con el trabajo infantil encontramos principalmente al Fondo para la Infancia de las Naciones Unidas, Unicef, y a la Organización Internacional del Trabajo, OIT, ambas sustentadas en los principios del Convenio 138 sobre la edad mínima, de 1973; de la Convención Internacional sobre los Derechos del niño y la niña, de 1989; el Programa Internacional para la Erradicación del Trabajo Infantil, IPEC, de 1992, y el Convenio 182 sobre las peores formas de trabajo infantil de $1999 .{ }^{1}$ Las definiciones aportadas desde estos organismos han servido como punto de partida para referirse a este concepto. Sin embargo, hay quienes señalan que éstas carecen de una discusión teórica sobre el trabajo, ya que "de ninguna manera explica lo que es el trabajo infantil como actividad en sí misma, ni lo que constituye a la infancia”, y que se trata, más bien, de un intento por "localizar aquel que, desde una óptica propiamente burocrática, debe abolirse” (Hernández, 2006: 26).

Unicef define el trabajo infantil "como cualquier trabajo que supere una cantidad mínima de horas, dependiendo de la edad del nińo o niña y de la naturaleza del mismo. Este tipo de trabajo se considera perjudicial para la infancia y por tanto debería eliminarse". Además, establece

\footnotetext{
${ }^{1}$ Los Convenios fueron instaurados por OIT con la finalidad de regular y erradicar el trabajo infantil en cualquiera de sus modalidades.
} 
ciertos criterios básicos para señalar que es inapropiado cuando: es con dedicación exclusiva a una edad temprana — menos de 12 ańos—, se destina muchas horas, provoca estrés físico, social o psicológico indebido, trabajan y viven en la calle en malas condiciones, el salario es inadecuado, tienen que asumir demasiada responsabilidad, limita su acceso a la escolarización, mina su dignidad y autoestima, le impide conseguir un pleno desarrollo social y psicológico.

OIT define como trabajo infantil "todo trabajo que priva a los niños de su niñez, su potencial y su dignidad, y que es perjudicial para su desarrollo físico y psicológico". Es decir, toda aquella actividad considerada física, mental, social o moralmente peligrosa o nociva para el niño, que interfiera en su proceso de escolarización, ya sea que lo prive de su posibilidad de ir a la escuela, que la abandone prematuramente o que se vea en la necesidad de combinar la asistencia a la escuela con altas exigencias relacionadas con un trabajo pesado y jornadas laborales intensivas (OIT, 2004). El trabajo infantil para OIT es percibido como un problema social, sinónimo de explotación laboral. Entre los motivos por los que se manifiesta en contra del trabajo infantil se nombran: les "roba su niñez" porque están sujetos a la explotación económica y a trabajar en "peores” o "peligrosas” condiciones; y les priva de la educación, lo cual puede contribuir a perpetuar la pobreza (Hernández, 2006; Rausky, 2009; Saadeh, 2011).

No obstante, OIT (2004) habla del trabajo infantil "aceptable" siempre y cuando "no afecte la salud de los niños", "ni su desarrollo personal", y tampoco interfiera con su escolarización. Además reconoce que las labores de ayuda a sus padres en la casa, colaborar en la empresa familiar o ganar dinero en vacaciones o fuera del horario escolar para sus propios gastos, es positivo para desarrollar el sentido de responsabilidad, la autoestima y el desarrollo afectivo y de habilidades que no perjudican al niño.

Saadeh (2011: 161) considera que este tipo de excepciones no son más que un "abordaje irrealy de doble moral" ya que, por un lado, "se castiga a la niñez pobre que trabaja en el campo y en países del tercer mundo”, y por otro lado "se invisibiliza a otra niñez que trabaja haciendo cine o en empresas dedicadas a desarrollar software o productos de Internet 
en Estados Unidos y otros países de primer mundo”. Otros autores señalan que muchas veces aquellos que defienden la erradicación son quienes promueven y avalan políticas neoliberales, mismas que generan e intensifican la pobreza de las familias (Rausky, 2009).

Pero, ¿cómo se llega a estas definiciones? Los argumentos que presentan las instituciones parten de los estudios académicos que éstas financian, de ahí que el posicionamiento académico que encontramos en variados libros y artículos no difieran de las definiciones antes expuestas, ya que la mayoría expresa en esencia lo mismo con algunos matices. "El trabajo infantil constituye una grave violación al derecho básico de la infancia: vivir su niñez ... violenta los derechos de los niños y las niñas y está marcado por las condiciones de ilegalidad en que se realiza, razón por la cual se oculta, excepto cuando tiene lugar en el ámbito callejero o en espacios públicos cerrados" (Barreiro, 2000: 148); también porque los priva de los servicios educativos, como se dijo anteriormente.

En contraste, entre los de valoración crítica encontramos a algunas organizaciones no gubernamentales y académicos que se inclinan por la posibilidad de que la infancia se desempeñe en trabajos de manera digna, que contribuyan a mejorar su desarrollo personal y economía familiar, sin vulnerar sus derechos ni su integridad (Liebel, 2003; Cussiánovich, 2006). En este caso, se considera el trabajo como un derecho y, a la vez, como un deber de "ayudar" dentro del núcleo familiar (Ramírez, 2007; Pérez, 2012), como un medio para formarse para la vida, para educar al adulto del mañana (Maureira, 2007), o como un medio para obtener bienes de consumo a través del dinero (Pico y Salazar, 2008).

Bajo esta visión, también se busca sustituir el término trabajo infantil por niñez trabajadora, y se promueve la cultura o movimientos de niños, niñas y adolescentes trabajadores, desde donde se defiende su "derecho a decidir" si trabajan o no. Se les considera como sujetos de derechos y no sólo como objetos, es decir, protagonistas de su vida "con capacidad de decidir lo que les conviene o no les conviene". El problema no es que la niñez trabaje, sino las "condiciones" en las que realizan esas actividades. Algunos de los principales objetivos de este 
movimiento son: participación e igualdad de derechos en la sociedad; reconocimiento del protagonismo de niños y nińas trabajadoras; derecho a trabajar en condiciones dignas y adecuadas; lucha contra toda forma de discriminación, violencia, pobreza y explotación, etcétera (Leyra, 2011).

Entre los principales exponentes de este segundo enfoque encontramos a Alejandro Cussiánovich (2006) y a Manfred Liebel (2003). Ambos autores rechazan la idea de continuar abordando el trabajo infantil desde una visión que ellos llaman adultocéntrica o paternalista, donde lo que prevalece es la opinión de los adultos sobre lo que es mejor para la niñez.

Este último expresa que es necesario, primero, no negar a la niñez trabajadora, ya que al no aceptarla se tiende a invisibilizarla y se contribuye a que siga trabajando, gran cantidad en la calle, en condiciones de explotación. De igual manera, comprender el trabajo desde el punto de vista de las mismas niñas, niños y adolescentes, qué significa para ellos, cómo lo viven y cómo lo valoran. "Esto requiere revisar nuestras propias escalas de valores y aceptar que los y las nińas ven su trabajo de manera distinta de la que nuestro entendimiento común nos sugiere" (Liebel, 2003: 24). Y Cussiánovich (2006) critica el hecho de que los convenios se muevan en torno a la prohibición, la eliminación, la sanción, la penalización del trabajo infantil, y no en dar valor y reconocer la vida y el trabajo de la infancia trabajadora. El hecho de entender que el trabajo es uno de los "ejes catalizadores de las grandes interrogantes", y los cambios que se han generado en torno al concepto, nos debe obligar a asumir nuevas dimensiones de análisis.

Durante mucho tiempo la discusión se ha agrupado en estos dos grandes bloques. Sin embargo, han surgido posicionamientos alternos en los que se advierte que para abordar el tema de la infancia trabajadora es necesario tener en cuenta "la diversidad de experiencias y representaciones que existen en torno al trabajo infantil, y comprender que las mismas no pueden desligarse de momentos históricos y culturas específicas" (Rausky, 2009: 699), así como "analizar el papel que la acumulación capitalista y los modos de producción juegan en la producción y 
reproducción de inequidades socioeconómicas tanto a nivel local como global" (Glockner, 2014: 136).

En estos estudios también se pronuncian en contra de que nińas, niños y adolescentes trabajen: consideran que efectivamente se violentan sus derechos humanos al desempeñar actividades en condiciones desfavorables (ibídem), y porque se intensifican las desigualdades entre la misma infancia, es decir, entre quienes trabajan y quienes no lo hacen (Rausky, 2009). A la vez, se tiene claro que en muchos casos el trabajo infantil es casi inevitable: por cuestiones de pobreza estructural en la que están inmersos — la cual debe ser intensamente cuestionada desde las causas que la producen y no solamente desde sus efectos, tales como culpar a madres y padres por involucrar y/o forzar a sus hijas e hijos a trabajar-; o porque lo consideran como parte de una práctica cultural donde éste representa una "ayuda" o "colaboración” familiar, lo que transforma el sentido del concepto mismo. El trabajo no es sólo una actividad económica sino también social, puesto que forma parte de un proceso educativo (Maureira, 2007), o de reciprocidad familiar (Ramírez, 2007), o una obligación moral. Sin embargo, cuando el trabajo que realizan bajo motivaciones sociales comienzan a hacerlo fuera del contexto familiar y éste adquiere un mayor valor monetario — para satisfacer la necesidad y subsistencia individual y/o familiar - tiende a convertirse en explotación mercantil. De ahí que considerarlo aprendizaje u obligación moral termine funcionando "como un mecanismo de naturalización o normalización de la explotación infantil (Morice, 2000, en Glockner, 2014: 165).

En varios de los trabajos se argumenta que el problema real no es que las niñas, niños de adolescentes lo hagan, sino las condiciones en que se ven obligados a realizarlo - largas jornadas, salarios precarios, todo tipo de violencia, etc. - ya que van en detrimento de su condición humana. También se afirma que lo fundamental es no restar importancia al trabajo que desempeñan para evitar invisibilizarlo; no clasificarlo en términos de valores - bueno o malo, mejor o peor- ya que limitaría entender el contexto bajo el cual se está desarrollando; además de que es indispensable reconocer que el trabajo infantil existe — sin caer en radicalismos burocráticos de abolición/erradicación o en argumentos 
que lo fomenten - con el propósito de poder intervenir e incidir en políticas públicas que transformen sustancialmente las condiciones de la infancia trabajadora; lo anterior, quizá, es el mayor reto que se tiene por delante.

Coincido en que la atención debe centrarse en las causas que lo derivan, en las condiciones que realizan las actividades laborales y en la manera en que ellos viven y conciben el trabajo — remunerado o nodesde sus experiencias personales y contextos sociales. Esto último nos permitirá comprender qué los motiva a migrar y trabajar dentro y fuera de Guatemala, cómo es el proceso de toma de decisión, así como las condiciones que rodean la misma.

\section{Algunas motivaciones para trabajar y para migrar entre la infancia de Guatemala}

La migración de trabajadores guatemaltecos, hombres, mujeres e infantes, hacia los municipios fronterizos de lado mexicano tiene una larga trayectoria histórica sobre la cual se ha escrito ampliamente. Hasta hace pocas décadas el trabajo que realiza la infancia comenzó a visibilizarse y a cobrar relevancia en el ámbito económico, político, social y académico. No sólo por los roles que ha tenido que desempeñar ante las serias circunstancias de precariedad familiar en las que se encontraba en su país de origen y la generación de recursos familiares que tiene cierto impacto en la economía nacional, sino también por las investigaciones e informes académicos que revelaron parte de las situaciones y condiciones que enfrenta mientras se emplea como fuerza de trabajo en el país de destino, específicamente en Tapachula, México (Arriola, 1995; Rivera, 2011; Blanco, 2012; Díaz et al., 2014, entre otros), contrario a las disposiciones de la Convención del Niño sobre sus derechos humanos, del Programa IPEC y de los Convenios $182 \mathrm{y}$ 138 establecidos por OIT.

De acuerdo con la información obtenida, es la búsqueda y desarrollo de trabajo económicamente remunerado lo que representa una de las motivaciones primordiales de la migración infantil transfronteriza guatemalteca. Pero ¿sólo es el trabajo y el dinero lo que motiva a esta población? $\mathrm{O}$ ¿hay otras motivaciones que compiten o complementan 
a la anterior? Aunque éstas pueden ser variadas y multifactoriales, existen condiciones históricas y culturales que frecuentemente posibilitan tanto la migración como el desempeño en actividades laborales.

A continuación expongo algunos argumentos obtenidos de la propia infancia en relación con qué los motiva a migrar y a trabajar, y lo que conlleva realizar ambas acciones desde el lugar de origen hasta el lugar de destino.

\section{¿En qué condiciones viven en el lugar de origen?}

En muchos relatos, las niñas, niños y adolescentes, expresaron a grandes rasgos cuáles eran las condiciones en las que vivían en sus hogares, en cuanto al ámbito económico, laboral, migratorio, de relaciones intrafamiliares, entre otras. La situación en la que se encontraba la mayoría era de precariedad, aunque había algunas excepciones, donde parecía que su contexto de vida era un poco menos desfavorable - habitaban casa propia con servicios básicos, podían asistir a la escuela superando el nivel básico, tenían acceso a una alimentación básica, por ejemplo-, debido a que sus padres contaban con un empleo formal, un pequeńo negocio propio o recibían remesas de familiares en Estados Unidos. Aunque muchas veces no era suficiente para solventar todas las necesidades familiares. Barre (2011: 83) señala que en Guatemala las remesas sostienen a hogares en áreas principalmente rurales y también urbanas, permiten mejorar la vivienda y las condiciones generales de vida, y suplen la escasa cobertura social [gubernamental] de los servicios de salud y educación.

Los departamentos de San Marcos, Quetzaltenango y Huehuetenango, pertenecientes al altiplano occidental, recibían más remesas en la primera mitad de la década del año 2000 (Dardón, 2005), y son de donde provenía la mayoría de la infancia con la que interactué en 2009 y 2013-2014. El contexto de pobreza que caracteriza la región tiene raíces históricas largas y profundas, en gran medida por consecuencia de las adversas condiciones geográficas y climáticas que limita la agricultura de subsistencia en pequeñas parcelas, también por la guerra civil que azotó a esta región durante más de treinta años, lo que provocó una migración forzada interna y externa que posteriormente 
se convirtió en migración externa, ${ }^{2}$ así como una naturalización de la violencia (ibídem); y por la escasa atención gubernamental posterior al conflicto.

De acuerdo con los datos de la Encuesta Nacional de Condiciones de Vida, Encovi, de 2014, más de la mitad de la población en el país vivía en condiciones de pobreza, 59.3\%; y ésta se intensificaba en áreas rurales, $76.1 \%$, y en poblaciones indígenas, $79.2 \%$. En cuanto a los Departamentos mencionados, reflejaron un aumento en la pobreza entre 2006 y 2014: Huehuetenango pasó de 71.3\% a 73.8\% y Quetzaltenango de $44 \%$ a $56 \%$. Se destaca que San Marcos tuvo una disminución en su porcentaje, de $65.5 \%$ a $60.2 \%$, aunque no explican a qué se debió este descenso y tampoco significa que las condiciones de vida mejoraran para la mayoría de la población, puesto que $22 \%$ de ésta se encontraba en pobreza extrema; mientras que Huehuetenango tenía $28.6 \%$ y Quetzaltenango 16.2\%, respectivamente. Además, Encovi revela que a nivel nacional $68.2 \%$ de niñas, niños y adolescentes - de 0 a 17 años — habitaba en hogares pobres, lo que favorecía la práctica del trabajo infantil.

Las familias de las que provenían eran numerosas, entre cuatro y ocho hermanas y hermanos; en varios casos había ausencia de madre, padre o ambos, a veces había inclusión de otros familiares: abuelos y abuelas, por ejemplo; muchos estaban inmersos en un ambiente de alcohol, de cigarro y de violencia intrafamiliar; y en la mayoría existía una tradición familiar generacional migratoria por trabajo, que permitía obtener los conocimientos y habilidades básicas para realizar alguna actividad laboral en particular, desenvolverse en el área de labor, establecer redes de apoyo y generar la confianza e ilusión para salir de casa a trabajar.

En cuanto a las condiciones de vida en sus hogares referían que, debido al número de integrantes, los diferentes espacios compartidos dentro de la casa resultaban pequeños, aunque no expresaban una notoria incomodidad por ello. Las viviendas estaban construidas de distintos materiales —láminas, nailon, vigas, palos, adobe, block,

\footnotetext{
2 Aunque ya existía la migración temporal hacia el lado mexicano desde el siglo XIX, principalmente para trabajar en el cultivo de café en algunas fincas, es decir, en determinados periodos de tiempo en que la producción requería de un mayor número de mano de obra.
} 
cartón, lonas, entre otros materiales - y constaban de tres a cuatro piezas — habitación, cocina, sala—. Hubo quienes mencionaron que sus viviendas tenían huertos de traspatio y otros que contaban con pequeñas parcelas cerca de casa donde cultivaban productos básicamente para el consumo familiar: maíz, frijol, papa, haba, chayote, algunas hortalizas y árboles frutales —durazno, manzana, ciruela, pera-. El hecho de que "ayudaran" de manera no remunerada en las actividades agrícolas tampoco significaba que a todos les gustara el trabajo en el campo, aunque de igual forma participaban, ya que gracias al cultivo de esos alimentos no faltaba algo para comer en casa.

En general, éstas eran las condiciones en las que se encontraban viviendo las niñas, niños y adolescentes en su lugar de origen, las cuales los motivaba a salir de casa y a trabajar de este lado de la frontera, sin perder el contacto con la familia y con la esperanza de mejorar sus precarias condiciones.

\section{¿Por qué salen de su lugar de origen?}

Una respuesta recurrente es "porque allá no hay trabajo, no podemos trabajar de chicleros o boleros porque eso no existe allá". Aunque no se puede pasar por alto el hecho de que existe un considerable número de infantes trabajando en las principales ciudades cercanas a sus hogares, entre las que destacan las cabeceras departamentales San Marcos, Quetzaltenango, Huehuetenango, y la ciudad capital, Guatemala.

La mayoría de ellos se emplea en el sector servicios, comercio y construcción, es así que muchos tienen su primera experiencia laboral antes de llegar a Tapachula o a cualquier otra ciudad fronteriza - ya sea como vendedores ambulantes, aseadores de calzado, pidiendo dinero en las calles, como ayudantes de construcción, empleadas del hogar, etc.- y también donde aprenden algunas estrategias de sobrevivencia —insertarse en redes de amistad, conocer reglas básicas de seguridad, etc.- - de esta manera hacen frente a sus miedos al salir de su hogar o incluso es como se "liberan" de las presiones y la violencia intrafamiliar. Aunque a veces adquieren esos aprendizajes de este lado de la frontera. Sin embargo, prefieren venir a México porque aseguran que "allá" ganan igual o menos y trabajan más. 
Otros dicen que “Tapachula es más bonito y está más seguro; allá en Guate hay mucho ratero". Considerar Tapachula por ser "más bonito" y "más seguro" o "porque hace calor" son otras de las particularidades por las que la infancia trabajadora opta por este lugar. Pero ¿qué significa para ellos "más bonito", "más seguro"? Cuando mencionan que "es más bonito" - lo comparan con sus "aldeas" de origen — se refieren al hecho de que es más grande, un tanto más colorido por las fachadas de las casas, que están más iluminadas las calles — por el alumbrado público y los comercios-, que hay más cosas para ver y comprar en las tiendas, que el parque central es grande y muy concurrido por los espectáculos que se presentan, que hay más carros y más ruido. "Allá en mi aldea no es como acá, allá es todo silencio, aburrido, en cambio acá está más alegre". Evidentemente, la diferencia entre el "aquí" y el "allá" tiene que ver con características propias de una ciudad "urbana" y una localidad "rural", aunque también de una concepción entre el "desarrollo" y el "atraso", entre la maquinaria del consumismo donde hay que trabajar para conseguir un ingreso económico que permita adquirir todo tipo de productos, bienes y servicios; y la oferta de mano de obra barata, cuyas condiciones de pobreza, marginación, falta de oportunidades y exclusión de políticas gubernamentales que contribuyan a mejorar su calidad de vida, están en continuo contraste y son traducidas por la infancia trabajadora como "más bonito" o "más aburrido".

\section{El papel de la familia en la toma de decisión para migrar y las redes de apoyo}

La participación de la familia — padres, hermanos, tíos, primos, etc.es importante no sólo en la toma de decisión y en el viaje inicial, también en la estructuración de las redes de apoyo que comienzan en el lugar de origen y se extienden al lugar de destino.

La primera vez que salen de sus hogares regularmente lo hacen en compañía de algún familiar ${ }^{3}$ o de amigos, quienes son el apoyo en el

\footnotetext{
${ }^{3}$ En 2009, varios niños y adolescentes — todos del sexo masculino- señalaron que fueron traídos por sus hermanos mayores que vivían en la ciudad — desde hacía varios años- para que se dedicaran a la venta de dulces o el aseo de calzado. En ese tiempo las cajas de dulces estaban concentradas en manos de particulares - a veces familiares - o de los comerciantes de negocios establecidos. Los particulares tendían a traer a sus hermanos menores, primos
} 
proceso de adaptación, de búsqueda de empleo y de conocer la dinámica cotidiana en la ciudad. Esa primera experiencia, en ocasiones, en los más pequeños genera tristeza al extrañar a su familia, amigos, espacios, etc.; miedo ante una ciudad y personas desconocidas, y resentimientos contra sus padres por autorizar su salida y traerlos aun en contra de su voluntad. Aunque la decisión no siempre es tomada ni alentada por los padres, sino es una iniciativa propia influenciada en gran medida por hermanos, tíos, primos, amigos o vecinos. La mayoría de la infancia trabajadora considera importante tener el consentimiento de sus padres, puesto que sabe que tendrá respaldo y llegarán en su auxilio en caso de una emergencia por enfermedad o por cualquier otro asunto que no pudiera resolver.

Muchos afirman que sus padres frecuentemente se oponen a que viajen hacia este lado de la frontera y, en algunos casos, tratan de persuadirlos ofreciéndoles el pago por el trabajo que realicen con ellos o diciendo que les van a comprar los artículos escolares y personales que requieran, con la finalidad de que permanezcan en sus hogares. Pese a este tipo de propuestas, ellos prefieren salir de casa porque dudan que vayan a ser cumplidas. No obstante, hay quienes - los menos- quieren salir a trabajar sólo por mera experiencia de hacerlo y de corroborar lo que los demás les han dicho sin que realmente tengan una "necesidad" de conseguir un empleo, ya que los padres pueden cubrir sus gastos. De cualquier forma, ante la firme decisión de salir a trabajar, los padres terminan cediendo la autorización, al parecer con mucho pesar.

Mis papás no querían que viniera a trabajar porque dicen que es peligroso, no sé, les da miedo y no me iban a dar permiso, pero como dijo mi hermanito [de 14 años]: "yo voy con ella, ya fue que con trabajos dijeron que sî”... Mi papá me dijo que pa’ qué quiero venir, que él me va a dar para mi estudio, mi ropa, mi zapato, pero es que luego no me dan. En cambio así, con mi propio dinero, compro lo que yo quiera, a mi gusto (Alicia, vendedora de dulces, 17 ańos, 3 de septiembre y 5 de noviembre de 2013, Tapachula, Chiapas).

o cualquier otro familiar menor de edad para trabajar en su negocio, a quienes les pagaban cincuenta pesos diarios por jornada. 
De este relato podemos observar dos situaciones. Por un lado, los padres, pese a que muestran oposición a que sus hijos se desplacen para trabajar a Tapachula y emplean estrategias de convencimiento con las que evitarlo, terminan otorgando su consentimiento. A decir de los propios actores, cuando deciden trabajar en alguna ciudad dentro del país muestran menos resistencia en otorgar el permiso, sobre todo si son enviados con familiares, amigos y conocidos para que los empleen. Por otro lado, cada vez que deciden salir de casa los hijos para trabajar tienen que solicitar el permiso correspondiente a sus padres, siempre y cuando sean solteros y al regresar continúen viviendo con ellos. Tal parece que esta lucha por conseguir la anuencia de los padres y éstos de negarla es parte del juego en el proceso de migrar, aunque también, como dice Blanco (2012: 51), no se trata de "un sentimiento de autoridad y control paternal, es una simple aprehensión comprensible como padre o madre a que su hija [o hijo], todavía una niña [o niño], abandone el núcleo familiar".

Otro aspecto importante en la primera salida, como en los demás desplazamientos, es establecer redes de apoyo desde el lugar de origen, ya que serán indispensables en el lugar de destino para conseguir empleo, tener un lugar donde hospedarse, aprender a conducirse en la ciudad, así también como mecanismo de defensa ante alguna situación que les resulte peligrosa o conflictiva o como lazo solidario ante dificultades de salud, dinero o de cualquier otro tipo.

¿Cómo construyen las redes de apoyo? A través de los lazos familiares entre padres, hermanos, primos, tíos, los cuales se extienden a amigos, vecinos, con quienes comparten intereses comunes y, como lo señala Lomnitz (2001), con quienes tienen intensos intercambios de información, de bienes y servicios, de ayuda laboral o apoyo moral. Sin embargo, los lazos de parentesco no necesariamente generan esas redes de intercambios recíprocos, ya que es posible ver cómo por ciertos conflictos tienden a separarse de algún familiar o amigo.

Aunque en muchos casos la decisión de trabajar y de migrar es tomada por los mismos infantes, detrás de ella existe el respaldo y/o la presión familiar para hacerlo, así como factores estructurales que los conducen a tomarlas; por ejemplo, la pobreza. No obstante, también 
se involucran aspectos subjetivos como la "ilusión", la "emoción”, y la búsqueda de "nuevos estilos de vida", las cuales son complementos motivacionales que propician la migración temporal de esta población.

\section{¿Por qué eligen trabajar en Tapachula?}

-Yo tengo ya 19 años [por su complexión física, parece tener menos edad]. Salí de mi casa la primera vez cuando tenía 12 años, bien chiquita. Yo quería seguir estudiando el básico, pero ya no me dieron porque tenían que darle a mis otros hermanos [ella no es la mayor, y tiene hermanos de menos edad].

- ¿Querias venir a trabajar?

—Pues la verdad, no mucho, pero allá [en su lugar de origen] no estaba haciendo nada [aunque sí ayudaba en las labores del hogar] y una tía me dijo que viniera, que acá [en Tapachula] hay trabajo, y vine para acá (entrevista a Angélica, Tapachula, Chiapas, 6 de abril de 2014).

Empecé a venir cuando tenía 16 años. Antes no porque como estudiaba el básico mis papás no me dejaban. Quise venir porque yo veía que mi primo cuando llegaba a su casa siempre tenía dinero. Como yo estudiaba, cuando tenía vacaciones nomás estaba ahí en la casa y no hacía nada. A veces le ayudaba a mi papá en el campo, pero nada más. Entonces me dijo mi primo que viniera a trabajar acá y vine con él (Daniel, Tapachula, Chiapas, 9 de diciembre de 2013).

La mayoría de los relatos expresan que su desplazamiento se debe a la posibilidad de conseguir trabajo mejor remunerado que el que pudiera tener en su país de origen. Eligen Tapachula porque es la ciudad más grande de la región, tiene importante actividad comercial y de servicios todo el ańo, tanto en el ámbito agrícola como urbano (Rivera, 2011; Caballeros, 2017), está ubicada muy cerca de la frontera - lo que les permite ir y venir a su casa constantemente, de forma documentada o no; mantener sus relaciones sociales con la familia y no sentirse fuera de Guatemala, dada la relación histórica regional entre ambos países- y ahí se encuentra algún familiar trabajando. Por otra parte, 
en el imaginario colectivo se mantiene la idea de que en este lugar "hay trabajo", "es más seguro", y que siempre encontrarán una actividad en la cual desempeñarse en cualquier época del año, en la calle o en algún negocio establecido, ya sea como empleado o generando sus fuentes de ingreso autoempleándose, que van desde vender dulces o asear calzado en las calles hasta tener responsabilidades específicas en un negocio establecido o en una casa - vendedor de tortas, ropa, tacos, pollos, aguas frescas, trabajadoras del hogar, entre otros.

Además del factor económico, se deja entrever que hay otros motivos que inducen a trabajar y a migrar, como el hecho de que las actividades que realizan en el hogar o en el campo, ${ }^{4}$ por no generar una ganancia económica tangible, no lo consideran trabajo - “con ellos no ganamos dinero y acá sî” - sino una obligación, de ahí que le resten importancia y signifique para ellos "no hacer nada" (Ramírez, 2007). Salir para emplearse en alguna actividad que les permita tener un ingreso económico, cuyo fin está destinado a contribuir en los gastos del hogar, principalmente para comprar alimentos, y para abastecer sus necesidades personales básicas, tiene más sentido que "no hacer nada" en casa.

Otro argumento está relacionado con el aspecto educativo. $\mathrm{Si}$ "no hacen nada" en casa y tampoco quieren o ya no pueden continuar estudiando, para ellos la única opción es trabajar. Incluso para quienes continúan estudiando, emplearse durante el periodo vacacional —de finales de octubre a mediados de enero- representa una recurrente

\footnotetext{
${ }^{4}$ En el caso de las mujeres, ayudan a sus madres con el trabajo del hogar — barrer, lavar, limpiar, hacer de comer, cuidar a los hermanos más pequeńos, etc.- y a sus padres en el campo o en el establecimiento comercial que posean - carnicería, farmacia, zapatería, venta de frutas y verduras, etc.- - Los hombres sólo colaboran con sus padres debido a que, culturalmente, está establecido que ellos no participen en el trabajo asignado a las mujeres. Los hombres mandan en la casa, no deben ser cuestionada su autoridad, aportan el dinero para el sustento de la familia, ejercen violencia intrafamiliar. Las mujeres deben ser sumisas, cariñosas, estar al cuidado de su esposo e hijos, si aportan dinero al sustento familiar no es reconocido, debe permanecer en su hogar pese a la violencia que pueda ser ejercida contra ellas. Las desigualdades de género en Guatemala son muy marcadas y se expresan mediante asignaciones de roles como los mencionados. Estos patrones de género continuamente se reproducen desde el seno familiar, de padres y madres a hijos e hijas, así como en el plano comunitario, de ahí que para muchas niñas, sobre todo adolescentes, salir del lugar de origen represente una oportunidad de escapar de estos patrones, aunque no lo expresen abiertamente como tal.
} 
alternativa, ya que las ganancias que obtienen les sirven para comprar útiles y uniformes escolares o los pasajes de traslado de su casa a la escuela y viceversa, que en ocasiones se ubica en una localidad vecina. También hay quienes tienen que hacer pausas durante su instrucción educativa para dar oportunidad a que las y los hermanos que están más adelantados la concluyan o a que los más pequeños la empiecen o continúen.

Estas estrategias nos muestran dos cosas: por un lado, que la dedicación a actividades laborales remuneradas en cortos periodos de tiempo puede reforzar e incluso garantizar la asistencia al siguiente ciclo escolar; y por otro, que suspender temporalmente sus estudios para trabajar muchas veces es una forma de asegurar la continuidad en ciclos posteriores. Ante la carencia de recursos económicos familiares que solventen los gastos para su educación, quienes quieren seguir estudiando normalmente han de buscar alternativas con las que obtener dinero que les permita cubrir esas necesidades. En ocasiones, el laborar llega a ser más atractivo que el estudio por la ganancia que obtienen mediante su fuerza de trabajo.

- Tuve que dejar de estudiar un año porque mi hermana está estudiando el diversificado y ya sólo le falta un año para terminar. Así que ella termine, entonces yo voy a seguir estudiando. Por eso vine a trabajar este tiempo [vendiendo dulces] para ahorrar un poco y cuando regrese a la escuela tenga dinero para comprar mis útiles, mis zapatos, el uniforme o para mi pasaje. Además que aprovecho a comprarme cosas que necesito ahora, por ejemplo, esta vez que fui a mi casa pasé a Malacatán a comprar un corte [que usan como faldas] para mí y para mi mamá, y una blusa. También ya compré mis zapatos y mi mamá me tiene dinero ahorrado [no sabe exactamente cuánto] para cuando entre a la escuela.

- ¿Tus papás te van a apoyar para que vayas a la escuela?

- Sí, pero como mi hermana estudia y tengo hermanos más chicos que también van a la primaria entonces ya no alcanza para todos.

(Alicia, Tapachula, Chiapas, 24 de julio de 2013.) 
Mi hermanito [Joel, 14 años] ya no quería regresar a estudiar, como que le ganó la ambición porque parece que ganaba bien ahí donde trabajaba [Joel era ayudante en un negocio donde venden pollos asados]. Me dijo: "ya no quiero ir a estudiar, es que acá gano bien; dile a papá que mejor me voy a quedar". Yo le dije que no, que trabajo siempre va haber, que él tiene que seguir estudiando si quiere ser alguien en la vida, tener un mejor trabajo que sólo asando pollo. También le dije que si no se regresaba que le iba a decir a mi papá y que se las arreglara con él, porque sólo tenía permiso para trabajar en las vacaciones. No le quedó más que irse (Braulio, Tapachula, Chiapas, 19 de febrero de 2014).

Finalmente, el clima es otro factor que parece incidir en la preferencia por Tapachula. Les gusta esta ciudad porque hace calor, ya que en su lugar de origen "hace mucho frío" "s "siempre andamos con suéter, con la piel toda rajada, a veces ni ganas de bañar da [rien]”. ¿Pero qué significa que haga calor? Lo que pude observar es que con el calor, en el caso de las mujeres, pueden descubrir un poco su cuerpo, con blusas de telas más ligeras y el uso de faldas, que si bien son gruesas, dicen que no les representa mayor molestia. También les permite el uso de todo tipo de sandalias y sienten que su piel es más suave y sus mejillas se mantienen enrojecidas. Es decir, el calor puede representar para ellas mostrar más su feminidad y sentirse más atractivas. Mientras que en los hombres el clima no tiene mayor relevancia en cuanto a su apariencia, pero sí en su rendimiento físico: "cuando hay mucho calor da sueño, cansa más caminar y da mucha sed". Sin embargo, el clima también representa riesgos para la salud de ambos, ya que por el intenso calor, las fuertes lluvias y los rayos del sol, suelen enfermarse de diarrea, insolación, gripa, tos, fiebre, les sangra la nariz o les aparecen manchas en la piel, entre los más comunes.

\footnotetext{
${ }^{5}$ La mayoría dice que son del Departamento de San Marcos y, particularmente, del municipio de Concepción Tutuapa; así como de Tajumulco, Tacaná, Comitancillo, Ixchiguan, entre otros. De esos municipios, los primeros tres están muy cerca de volcanes y se enmarcan dentro del altiplano occidental, junto con los Departamentos de Quetzaltenango, Huehuetenango y Totonicapan, cuyas elevaciones montañosas alcanzan una altura mínima de 1,400 msnm con clima que varía de templado a semifrío (ver más en la página del Instituto Nacional de Sismología, vulcanología y meteorología de Guatemala. Zonas climáticas de Guatemala, disponible en http://www.insivumeh.gob.gt/meteorologia/zonas\%20 climaticas.htm.
} 


\section{Algunos factores subjetivos que motivan la migración temporal}

Cuando hablamos sobre sus motivaciones para migrar, primero mencionaban que iban a Tapachula porque querían trabajar, agregando enseguida: "porque acá es más bonito", “más alegre”, "hace calor”, es "diferente a mi aldea". Otros simplemente dicen: "vine porque quería conocer", y el trabajo queda en un segundo término. Este tipo de respuestas son cada vez más frecuentes entre la infancia trabajadora guatemalteca (Blanco, 2012), pero no es exclusivo de ellos, tal como nos lo muestra el trabajo de Aquino (2012: 47) con jóvenes migrantes de Oaxaca que residen en la ciudad de Los Angeles, California. La autora señala que las motivaciones subjetivas se generan en función de dos situaciones: "la búsqueda de nuevos estilos que les permita la movilidad física y social", y "la búsqueda de un nuevo modelo familiar y de pareja".

En cuanto a la primera, encontré que la infancia de Guatemala sale de casa para conocer nuevos lugares, en este caso, la ciudad de Tapachula. A más de uno se le escuchó decir que llegan por la curiosidad de conocer y que les gustaría ir a otros municipios y estados de los que familiares, amigos o conocidos les han platicado, tales como Tuxtla, San Cristóbal, Oaxaca, Playa del Carmen, Cancún y, por supuesto, Estados Unidos.

Tengo una amiga que se fue a trabajar a Oaxaca, no sé en qué parte, pero ahí está. Dice que está bonito y que gana más. A mí me gustaría ir un día a conocer, pero dice que a veces la policía detiene a los que son de Guate ...También tengo una amiga vendiendo allá en el parque, dice que es de San Cristóbal. Me cuenta que allá también hace frío como en mi aldea, pero que está bonito. Algún día voy a ir también ahí ... ¿por qué no me llevas contigo cuando vas? (Mariana, Tapachula, Chiapas, 18 de octubre de 2013).

Aunque exista en ellos la inquietud del desplazo territorial hacia otros lugares para "conocer" o trabajar, la mayoría no planea quedarse a vivir fuera de casa en el futuro, lejos de su familia; aunque hay excepciones. Tapachula sólo es considerado como un espacio de trabajo, donde 
pueden conseguir capital económico y social que les permita acceder a otros niveles y modelos de vida en su "aldea", los cuales se han ido construyendo a partir de lo que les llega de fuera mediante los medios de comunicación y lo que en la misma localidad se reproduce - comprar una casa, terreno y/o carro; adquirir artículos como computadoras de escritorio o tabletas, celulares, ropa y calzado de mejor calidad; ayudar a la familia; continuar sus estudios para tener un mejor empleo en la etapa adulta, etc. - . La pobreza económica y social en las que están inmersos aunadas a la esperanza de acceder a "nuevos" modelos de vida es lo que, en general, motiva a la infancia trabajadora, como a las generaciones siguientes, para trabajar y para migrar.

Con respecto a la movilidad por búsqueda de nuevo modelo familiar y de pareja, Aquino (ibídem) menciona que las actuales generaciones han comenzado a realizar cambios de mentalidad que inciden en algunas prácticas comunitarias, sobre todo en las relaciones de género. En el caso de las y los adolescentes guatemaltecos, no dudo de que en algunos se hayan generado ciertos cambios de mentalidad, por lo menos se da en el discurso y no necesariamente en la práctica, por ejemplo que defiendan su derecho a no casarse a temprana edad, a una igualdad de derechos y obligaciones entre hombres y mujeres, a trabajar en actividades que eran consideradas sólo de hombres o de mujeres, a cambiar su estilo de vestir y calzar, entre otras.

Pero en la mayoría persisten ideas bastante arraigadas en cuanto a los roles de género, las cuales trascienden la frontera. Por ejemplo, son las mujeres las que se deben dedicar al trabajo en el hogar y de los hijos, de ahí que las chicas generalmente prefieran desempeñarse en esta actividad o afines (Rivera, 2011; Blanco, 2012). Otra idea es que ellas "deben portarse bien" fuera de casa y que su conducta debe ser apropiada para su género — educada, trabajadora, sumisa, cuidar su lenguaje, evitar exhibir su cuerpo, no fumar o consumir alcohol, etc.- - de lo contrario son señaladas y juzgadas por los demás. Los hombres parecen tener mayor permisibilidad para transgredir la "norma" sobre estas conductas. No obstante, también han de lidiar con algunas prácticas establecidas, como el hecho de que no deben esperar mucho tiempo para contraer matrimonio o ser padres. 
Muchos de ellos deciden salir porque intentan deslindarse de las presiones y restricciones familiares $y$, aunque hasta cierto grado lo logran, el hecho de que la ciudad destino no se encuentre tan distanciada de los lugares de origen, no les permite tener toda la libertad de "hacer lo que quieran”. Tal parece que el control familiar y, también, el comunitario se extienden más allá de las fronteras a través del "chisme", como una práctica sociocultural que regula la conducta colectiva e individual de quienes participan en él.

Después de que llegamos acá, mis amigas empezaron a cambiar, y más porque dos de ellas ya tienen dizque novio. Cuando estamos allá no tienen porque sus papás les regañan, pero acá no tardaron nada y buscaron su novio, se ponen otra ropa, se pintan ... Yo no hago eso porque no me gusta, no voy a ser una persona acá y otra allá. Además, lo que haga acá todo se enteran rápido en mi casa. Es que hay gente chismosa que me conoce y me ve qué estoy haciendo. Ahí está, esta vez que hablé por teléfono con mi mamá me estuvo preguntando cosas, ella ya sabía todo lo que hago acá antes de que yo llegara, porque le fueron a decir, y como no tengo nada de qué avergonzarme le platiqué todo a mi mamá. Si no fuera así, ella no me dejaría venir otra vez (Yeni, Tapachula, Chiapas, 5 de febrero de 2014).

En mi aldea [Departamento de Huehuetenango], el gobierno es de uso y costumbre. Ahí antes de salir tenemos que avisar a la autoridad que vamos a venir a trabajar. Ellos nos autorizan y nos dicen que nos portemos bien, que vamos a venir a trabajar no a robar. Que de por sí nuestros hermanos mexicanos ya nos tienen visto como que los de Guatemala somos flojos, rateros, entonces que no hagamos cosas malas para que no sigan pensando así ... Una vez un chavo vino y robó, pero no faltó quien avisara a la autoridad, fue su propio amigo con el que vivía. Primero le mandaron aviso de que fuera, y como no llegó entonces vino la autoridad a traerlo para llevarlo a la aldea y castigarlo. Por eso mejor hay que trabajar, si a eso viene uno, porque siempre estamos vigilados y nosotros vigilamos a los otros (Kevin, Tapachula, Chiapas, 28 de enero de 2014). 
Dada la "indisciplina" que pueda surgir fuera de casa, quienes tienen la autoridad sobre ellos, principalmente madre o padre, previo a la salida establecen acuerdos intrafamiliares relacionados con su comportamiento en la ciudad y con la obligación de mantener comunicación permanente a través de familiares, amigos o por teléfono; ${ }^{6}$ de lo contrario, les imponen algunas sanciones en función de lo que hayan hecho: desde negarles firmemente la autorización de volver a Tapachula, ser enérgicamente reprendidos, hasta ser víctimas de golpes físicos, sobre todo cuando la falta ya existe. El requerimiento de comunicación es más enfático para las niñas y las mujeres adolescentes que salen por primera vez de casa.

En este sentido, podemos ver que el control que hay por parte de la familia o la comunidad tiene su fuerza en la disciplina, ejercida mediante las miradas de esos otros con los que comparten espacios fuera de la aldea, y la autodisciplina, las cuales fueron previamente apropiadas y corporizadas, aunque en ocasiones es posible romper con éstas en distintas circunstancias.

Cualquiera que sea la razón para migrar, las niñas, niños y adolescentes tienen el mismo objetivo, buscar y conseguir establecerse por periodos cortos de tiempo en empleos que les generen un ingreso económico, aunque muchas veces no alcance para resolver sus necesidades ni las de sus familias.

\section{Consideraciones finales}

Discutir el tema sobre trabajo infantil en función de si es bueno, malo, educativo, perjudicial, cultural, participativo, social, etc., nos lleva a entender la complejidad que presenta esta realidad no sólo por la variedad de posicionamientos que existen entre quienes defienden ese derecho y quienes se manifiestan en contra, sino también por las motivaciones que cada familia y miembro de la infancia trabajadora tiene para decidir si trabaja o no. Aunque dichas motivaciones son diversas, es preciso reconocer que existen causas estructurales de tipo económico, político, histórico y cultural — tales como la pobreza, la migración

\footnotetext{
${ }^{6}$ El domingo es normal verlos hablar con sus familiares desde el celular, teléfono público o caseta telefónica.
} 
laboral, la falta de estímulos y oportunidades educativas, el desempleo o empleos mal remunerados, entre otras-; que los lleva a tomar esas decisiones, de manera individual y/o colectiva; así como a asumir, de forma consciente o no, los riesgos que conlleva salir de casa y emplearse en actividades precarias que puedan afectar su integridad física, psicológica o incluso moral.

El trabajo remunerado a temprana edad, muchas veces fuera de casa y del alcance familiar, es percibido de distintas maneras: no sólo como un medio para obtener recursos económicos que solventen sus necesidades más inmediatas y las de su familia, sino además como una experiencia de vida que permite fortalecer sus relaciones sociales, consolidar su capacidad de agencia para decidir y sobrevivir en un lugar lejos del hogar, ampliar sus conocimientos, habilidades y aprendizajes fuera del ámbito escolar formal y elevar la autoestima al ganar su propio dinero. También ha logrado producir algunas transformaciones en ellos, en su entorno familiar y comunitario, en cuanto a pensamientos y conductas para tratar de hacer frente a viejas prácticas sólidamente institucionalizadas que aún se siguen reproduciendo, sobre todo, en función de los roles de género.

La mayoría de niñas, niños y adolescentes entrevistados no consideran que el trabajo sea un factor que les impida ir a la escuela ${ }^{7}$ o un mecanismo que vulnere sus derechos básicos a una "infancia feliz"; tampoco una vía hacia la explotación — por sí mismos y por otros-, a la discriminación, al peligro y a la violencia, situaciones por las cuales buscarán ser "protegidos” institucionalmente — por el Estado, organismos internacionales o asociaciones civiles-. El trabajo remunerado y fuera de casa es algo que tienen que hacer tarde o temprano, casi siempre acompañados e instruidos por familiares y/o amigos. En su cotidianidad, lo que prevalece son las ganas de "salir adelante". Visualizan la precariedad y las malas condiciones en las que están inmersos, no obstante la victimización no les sirve de nada.

\footnotetext{
${ }^{7}$ Tampoco asistir a la escuela y terminar un grado de estudio es garantía para desempeñarse en empleos mejor remunerados. Esto más bien depende de los aprendizajes y habilidades que vayan adquiriendo a partir de sus experiencias laborales. De ahí que estudiar no tenga tanta relevancia para ellos como sí para las instituciones y académicos que se oponen al trabajo infantil.
} 
Se destaca que el trabajo remunerado llevado a cabo por la infancia se da al margen de una serie de leyes gubernamentales que en teoría lo permiten bajo ciertos criterios para regularlo o en definitiva restringirlo. En la práctica existe una enorme permisividad, y dado que la regulación está ausente, se desarrolla en condiciones desfavorables: bajos salarios, largas jornadas, violencia física, psicológica y sexual, discriminación, etc. Esto conlleva a invisibilizar sus condiciones precarias como trabajadoras/es y a normalizar la violencia que se ejerce sobre muchos de ellos/as al encontrarse en relaciones asimétricas y de dominación con el/la empleadora, dada su condición de infancia, estancia indocumentada en México y fuerza laboral poco especializada.

La erradicación del trabajo infantil, como lo proponen algunas instancias internacionales y académicos, está lejos de ser una realidad. No porque esta infancia y sus padres se empeñen en querer trabajar, sino también porque la precariedad en la que se desarrollan obedece a problemáticas más amplias no resueltas, las cuales carecen de voluntad política, de política pública y de presupuesto para contrarrestarlas. Ante esta situación, las ratificaciones y firmas de Convenios por parte de las autoridades involucradas no sirven de nada. La infancia continuará buscando empleos remunerados para sobrellevar la precariedad en la que se encuentra ante la falta de iniciativas gubernamentales que promuevan un cambio de vida.

Me parece que lo más pertinente es planear e implementar acciones legales y sociales encaminadas a atender y mejorar sus condiciones de trabajo, por ejemplo poner al alcance y de forma explícita la información sobre sus derechos humanos y sus derechos laborales; y como migrantes, sancionar los abusos, crear mecanismos y espacios que lleven a la reflexión y a la sensibilización sobre el trabajo de la infancia migrante, entre las principales que se pueden atender. 


\section{Bibliografía citada}

Aquino, Alexandra, 2012, "Subjetividades juveniles y migración internacional. Ecos desde la Sierra Norte de Oaxaca”, en Yerco Castro (coordinador), La migración y sus efectos en la cultura, Conaculta, México, pp. 43-60.

Arriola, Aura Marina, 1995, Tapachula, "La perla del Soconusco", Ciudad estratégica para la redefinición de las fronteras, Flacso Guatemala, Guatemala.

Barre, Camille, 2011, "El impacto de las remesas en Guatemala. ¿Alivio a la pobreza o factor de desarrollo?, Transpasando fronteras. Revista estudiantil de procesos transnacionales, núm. 1, [en línea] disponible en https://www.icesi.edu.co/revistas/index.php/ trans-pasando_fronteras/article/view/1298/1728 [fecha de consulta: 21 de marzo de 2015].

Barreiro García, Norma, 2000, “El trabajo infantil, un concepto de difícil consenso", en Norma Del Río (coordinadora), La infancia vulnerable de México en un mundo globalizado, UAM, Unicef, México, pp. 147-167.

Blanco A., Blanca, 2012, "No me puedo dejar". Negociación y resistencia en el empleo doméstico. Aproximación a la capacidad de agencia de las empleadas domésticas guatemaltecas en Tapachula, Chiapas, tesis de maestría, CIESAS Sureste, San Cristóbal de Las Casas, Chiapas, México, agosto.

Caballeros, Álvaro, 2017, “Migración fronteriza de niños, niñas y adolescentes mam: entre la exclusión histórica y la seguridad migratoria”, Revista Ciencias Sociales y Humanidades, vol. 4, núm.1, [en línea] disponible en http://digi.usac.edu.gt/ojsrevistas/ index.php/csh/article/view/454/262 [fecha de consulta: 26 de enero de 2018].

Cussiánovich Villarán, Alejandro, 2006, “Tipología del trabajo infantil desde el punto de vista de los derechos humanos: la necesidad de una diferenciación", Ensayos sobre infancia. Sujetos de derechos y protagonistas, Ifejant, Lima, Perú, pp. 322-343, [en línea] disponible en http://www.ifejant.org.pe/Archivos/PDF/ 
ensayos_sobre_infancia.pdf [fecha de consulta: 13 de mayo de 2017].

Dardón, Juan, 2005, "Pobreza, migración internacional y regiones excluidas", Cuadernos de Guatemala, noviembre, números 10-11, [en línea] disponible en http://www.aapguatemala.org/03_publicacions/cuadernos/descarrega/10Pobreza\%20y\%20migracion.pdf [fecha de consulta: 4 de marzo de 2015].

Díaz P., Gabriela et al., 2014, "Las trabajadoras migrantes centroamericanas en Chiapas. Recomendaciones de política pública para garantizar el ejercicio de sus derechos”, Imumi, ONU Mujeres, [en línea] disponible en http://imumi.org/attachments/2015/ trabajadores-migrantes-centro.pdf [fecha de consulta: 11 de abril de 2015].

Encuesta Nacional de Condiciones de Vida, Encovi, Guatemala, 2014, disponible en https://www.ine.gob.gt/sistema/ uploads/2016/02/03/bWC7f6t7aSbEI4wmuExoNR0oScpSHKyB.pdf [fecha de consulta: 15 de marzo de 2018].

Glockner, Valentina, 2014, Trabajo infantil y regimenes de gubernamentalidad: slums flexibles, ongs y producción de subjetividades en la India contemporánea, tesis de doctorado, Universidad Autónoma Metropolotana Iztapalapa, México, D.F., marzo.

Hernández R., Edy, 2006, "Una crítica a la definición convencional del trabajo infantil", Revista Mundo Siglo XXI, verano, [en línea] disponible en http://www.mundosigloxxi.ipn.mx/index. php?option=com_content\&view=article\&id=14:n05\&catid=13:v olumen-ii\&Itemid=15 [fecha de consulta: 24 de octubre de 2015].

Instituto Nacional de Sismología, Vulcanología y Meteorología de Guatemala. Zonas Climáticas de Guatemala, disponible en http://www.insivumeh.gob.gt/meteorologia/zonas\%20climaticas.htm [fecha de consulta: 21 de abril de 2016].

Leyra, Begońa, 2011, "Aproximaciones antropológicas a la infancia trabajadora: Deconstruyendo los mitos y analizando los vacíos de una compleja relación”, en M. Jociles, D. Poveda y A. Franzé (coordinadores), Etnografías de la Infancia: Discursos, Prácticas 
y Campos de Acción, Los libros de La Catarata, Madrid, pp. 3759, [en línea] disponible en https://www.uam.es/otros/fmee/ documentos/leyra_fmee130209.pdf [fecha de consulta: 15 de noviembre de 2014].

Liebel, Manfred, 2003, Infancia y Trabajo. Para una mejor comprensión de niños y niñas trabajadores de diferentes culturas y continentes, Ifejant, Lima, Perú.

Lomnitz, Larissa, 2001, "Mecanismos de articulación entre el sector informal y el sector formal urbano, Redes sociales, cultura y poder. Ensayos de Antropología Latinoamericana, Flacso, México, pp. 99-134.

Maureira E., Fernando, 2007, “El trabajo infantil: una aproximación antropológica”, en David Robichaux (compilador), Familia y Diversidad en América Latina. Estudios de casos, Clacso, Buenos Aires, pp. 275-285.

Oficina del Alto Comisionado para los Derechos Humanos, Convención sobre los Derechos del Niño 1989, disponible en https://www.ohchr.org/sp/professionalinterest/pages/crc.aspx [fecha de consulta: 7 de abril de 2016].

OIT, 1973, Convenio 138 sobre la edad mínima, disponible en https://www.ilo.org/dyn/normlex/es/f?p=NORMLEXPUB: 12 100:0::NO::P12100_ILO_CODE:C138 [fecha de consulta: 7 de abril de 2016].

OIT, 1992, Programa Internacional para la Erradicación del Trabajo Infantil, IPEC, disponible en http://www.ilo.org/ipec/ programme/lang--es/index.htm [fecha de consulta: 7 de abril de 2016].

OIT, 2004, Trabajo infantil. Un manual para estudiantes, disponible en https://www.ilo.org/ipec/facts/lang--es/index.htm [fecha de consulta: 25 de septiembre de 2014].

OIT, s.a., Convenio 182, [en línea] disponible en http://www.ilo.org/ ipec/programme/lang--es/index.htm, http://www.ilo.org/ipec/ facts/ILOconventionsonchildlabour/lang--es/index.htm [fecha de consulta: 7 de abril de 2016]. 
Pérez, Norma, 2012, Socialización y trabajo desde la perspectiva de li tsebetikexch'iukkeremetike (niñas y niños) trabajadores, tesis de maestría, CIESAS Sureste, San Cristóbal de Las Casas, Chiapas, México, diciembre.

Pico M., María E. y Myriam Salazar H., 2008, "El trabajo infantil como práctica de crianza: contexto de una plaza de mercado", Revista Hacia la Promoción de la salud, enero-diciembre, [en línea] disponible en http://promocionsalud.ucaldas.edu.co/ downloads/Revista13_6.pdf [fecha de consulta: 13 de julio de 2015].

Ramírez, Martha A., 2007, "Helping at home. The Concept of Childhood among the Nahuas of Tlaxcala, Mexico", en Beatrice Hungerland y Manfred Liebel (eds.), Working to Be Someone. Child Focused Research and Practice with Working Children, Jessica Kingsley Publishers, Londres, pp. 87-95.

Rausky, María, 2009, “¿Infancia sin trabajo o Infancia trabajadora? Perspectivas sobre el trabajo infantil”, Revista Latinoamericana de Ciencias Sociales, Niñez y Juventud, julio-diciembre, [en línea] disponible en http://www.redalyc.org/pdf/773/77315614005. pdf [fecha de consulta: 14 de octubre de 2015].

Rivera, F., Carolina, 2011, "El trabajo de niñas, niños y adolescentes guatemaltecos en el Soconusco, Chiapas", en Daniel Villafuerte Solís y María del Carmen García Aguilar (coordinadores), Migración, seguridad, violencia y derechos humanos. Lecturas desde el sur, Unicach, México, pp. 257-290.

Saadeh R., Ana, 2011, "Niñez y adolescencia trabajadora: Un asunto de doble moral", Revista Iberoamericana sobre Niñez y Juventud en Lucha por sus Derechos, mayo-noviembre, [en línea] disponible en https://www.uam.mx/cdi/pdf/s_doc/rayuela4.pdf [fecha de consulta: 11 de junio de 2016].

Unicef, s.a, "Definición de trabajo infantil”, [en línea] disponible en https://www.unicef.org/spanish/protection/index_childlabour. html [fecha de consulta: 25 de septiembre de 2014]. 